\title{
BioRem-Database for Remediation of Heavy Metal Rich Habitats and Protection of Their Biodiversity
}

\author{
Lukas Nebel $^{1}$, Gerhard Kreitner, ${ }^{1,2}$, Othmar Horak ${ }^{1}$, Wolfram Adlassnig ${ }^{1}$, Gregor Eder ${ }^{1}$, \\ Edwin Palomino $^{3}$, Mario Leyva ${ }^{3}$, Irene Lichtscheidl ${ }^{1^{*}}$
}

${ }^{1}$ Core Facility Cell Imaging and Ultrastructure Research, University of Vienna, Vienna, Austria; ${ }^{2}$ blp GeoServices lim, Vienna, Austria; ${ }^{3}$ Universidad Nacional Santiago Antúnez de Mayolo, Huaraz, Perú.

Email: *irene.lichtscheidl@univie.ac.at

Received April 16 ${ }^{\text {th }}, 2013$; revised May 17 ${ }^{\text {th }}, 2013$; accepted June $15^{\text {th }}, 2013$

Copyright ( 2013 Lukas Nebel et al. This is an open access article distributed under the Creative Commons Attribution License, which permits unrestricted use, distribution, and reproduction in any medium, provided the original work is properly cited.

\begin{abstract}
BioRem is an open access on-line resource, which aims to document the biodiversity of terrestrial heavy metal rich sites around the globe that are the habitats of specialized metal tolerant organisms (MTOs). A comprehensive inventory of MTOs together with an analysis of environmental conditions and research about the adaptations of MTOs shall support the development of holistic models about the functioning of heavy metal ecosystems and lead to an improved understanding of interactions and adaptation strategies of MTOs. Furthermore, the database enables the identification of plants and microorganisms suited for remediation actions where protection of the population and the environment is needed. Information about scientific data shall lay the ground for the definition of heavy metal habitats with unique biocoenoses as reservoirs of biodiversity: accordingly, BioRem shall be a resource for education and for dissemination of our knowledge about the ecology of heavy metal rich sites and their habitats, and it shall provide tools for the evaluation of socio-economic strategies for either remediation or preservation of heavy metal habitats. Where needed, alternative strategies for the survival of MTOs shall be developed, hence contributing to the aim of the Göteborg 2010 target to halt loss of biodiversity.
\end{abstract}

Keywords: Ecology; Heavy Metals; Metallophytes; Plant Tolerance; Biodiversity Phytoremediation

\section{Introduction: Life in Habitats Contaminated by Heavy Metals}

Toxic concentrations of heavy metals (HMs, here defined as elements with a specific weight $>5 \mathrm{~g} \cdot \mathrm{cm}-3$ in the metallic state) in soil occur either from natural ore outcrops, serpentine rock and other geoanomalies, or from manmade metal mining, smelting and metal processing. Metals can be differentiated into elements essential for organisms (Fe, $\mathrm{Cu}, \mathrm{Mn}, \mathrm{Zn}$, Ni Cr, Co, Mo), such without known effects (V, W, Sn) and those that are always toxic $(\mathrm{Pb}, \mathrm{Cd}, \mathrm{Hg}, \mathrm{Pt})$. However, at supra-optimal levels all heavy metals become toxic. This threshold level is specific for each organism, ecotype and element $[1,2]$.

Only few species (MTOs, metal-tolerant organisms) have evolved sophisticated mechanisms to control metal homeostasis at the levels of uptake, distribution, sequestration and export, and to survive and propagate in toxic environments better than others [3-5].

\footnotetext{
"Corresponding author.
}

MTOs—including plants, fungi and bacteria—are of special interest, since some of them, so far mainly plants, are candidates for the improvement of HM sites. Some plants are capable of accumulating valuable HMs ("phyto-mining", [6]), of removing HMs from the soil ("phyto-extraction", [7]) and of preventing leaching of HM into the environment ("phyto-stabilisation", [8]), thus leading to phyto-remediation of the soil. Fungi may increase the metal resistance of plants by forming mycorrhiza, and bacteria may crucially influence the bioavailability of toxic elements. On the other hand, little is known on the role of the soil fauna, on the differing effects of different metal rich ore minerals, and on the interaction of all these parameters with each other. In order to gain a comprehensive image of the biodiversity and adaptations of MTOs, we therefore need to overcome fragmentation of knowledge by accumulating and summarizing existing information about the ecology of HM sites and their biodiversity.

Remediation of toxic HM soil is of paramount socio- 
economic importance in order to ensure that humans are provided with an environment as healthy as possible. On the other hand, removal of contaminated sites inevitably causes the loss of habitats for MTOs, hence threatening them into extinction, maybe even before we have learnt to know them. It is therefore important to understand the complex relationships between HM pollution and ecology before remediation of HM polluted sites can be applied correctly. Furthermore, it is crucial to distinguish between HM polluted habitats which pose a threat for humans and the environment, and those successfully stabilized by their biocoenoses; the latter can serve as models for the study of the ecology of HM rich habitats and of the strategies of their host organisms for tolerating HM stress.

The aim of this database therefore is to document the biodiversity of terrestrial heavy metal rich habitats, which are the homes of specialized metal tolerant organisms. It shall lead to a holistic model about the functioning of heavy metal ecosystems, to an improved understanding of interactions and survival strategies of MTOs, and to the identification of plants and microorganisms suitable for remediation actions where protection of the people and the environment are needed. BioRem shall be a resource for education and for dissemination of knowledge about the functioning of heavy metal sites and their MTOs, and it shall help in deciding about best practice for remediation actions and for plant conservation.

The database has been developed in the frame of the EU project Umbrella (EU 226870), of the Austrian EAD/ Appear project BioRem (Appear 43) and of the bilateral project Promote between Austria and Romania (WTZOEAD RO-08/2012). It is interlinked with the Global Metallophyte Database [9], a leading database about metal-tolerant plants, and with ISES, the website of the International Serpentine Ecology Society. ISES gives information about habitats on metal rich serpentine bedrock and their metal tolerant plants [10]. We also draw attention to a list of metal hyperaccumulating plants provided on the internet [11]. In providing BioRem, we invite colleagues world-wide to contribute their experience of heavy metal rich sites and their biodiversity.

\section{Expected Results from the Database Biorem}

BioRem is created as a platform for the exchange of information from biodiversity and ecophysiology research on heavy metal ecosystems. It shall lead to an inventory of MTOs and promote our understanding of the ecology of HM polluted habitats as well as of adaptation strategies of MTOs. Accordingly, we want to contribute information to fundamental questions concerning:

- Structure and diversity of heavy metal biocoenoses by assessing genetic diversity and distribution: 1) gain a comprehensive inventory of MTOs, including not only vascular plants but also mosses, lichens, terrestric algae, animals and microorganisms; 2) identify specialised phenotypes, genotypes and ecotypes originating from different HM rich areas; 3) evaluate their status of threat.

- Environmental conditions and functioning of HM ecosystems: 1) study the environmental conditions that typically add to heavy metal stress including high solar irradiation, extreme temperatures, drought, low nutrient supply and radioactivity; 2) correlate these conditions with geology, mineralogy and metal content of bedrock and soils as well as the occurrence of specific MTOs; 3) assess the influence of other important factors like herbivory and human perturbation.

- Adaptation strategies of MTOs: 1) identify the structural base for heavy metal homeostasis, including morphological, anatomical and ultrastructural approaches; 2) analyse physiological reactions to heavy metal stress, integrating results from research fields as diverse as genetics, proteomics, cell biology, classical physiology and evodevo-research; 3) establish new model systems of MTO-research in the fields of bryology, mycology and microbiology.

- Closing the gap between mineralogy and diversity research: 1) identify the major HM minerals present at HM contaminated habitats, especially mining sites; 2) correlate the occurrence of specific minerals with other abiotic conditions like redox potential, $\mathrm{pH}$ and water regime; 3) correlate the occurrence of HM minerals and specific MTOs.

- Survival strategies on the community level: Vascular metallophytes live in close contact with specialised fungi and bacteria that may influence the bioavailability of heavy metals and may be stimulated or inhibited by the plants via exudates. We want to accumulate information about how these communities are structured and if key species can be identified. This may add to the question if the transfer of whole communities could provide a superior strategy for phytoremediation compared to the conventional planting of isolated HM tolerant vascular plants.

- Need for remediation or conservation of heavy metal ecosystems: 1) identify plants suited for remediation; 2) define specific heavy metal habitats with unique biocoenoses as reservoirs of biodiversity; 3) hence contribute to the aim of the Göteborg 2010 target to halt loss of biodiversity.

In addition, sharing information shall add to developing a network of scientists and stakeholders with multidisciplinary background, and hence create a synoptic environment for education and research in the field of metal-rich ecosystems. 


\section{Layout of the Database}

We set up a frame system that is based on the Wordpress content management system (http://wordpress.org/). The advantages of Wordpress include both easy setup and easy use. Compared to the construction of a custom platform, the use of Wordpress results in a considerable reduction of cost for setup and maintenance, as it is equipped with an own, built in database and user management. In order to provide easy access for the worldwide scientific community, the database is set up in English.

Currently a development version is available at http://www.univie.ac.at/biorem. We start to integrate data of various habitats in order to check for the applicability of the suggested topics, and we invite our colleagues to contribute their expertise in order to see if the system is able to mirror the actual situation of the fields.

At the present state, we invite information about HM habitats by mail to irene.lichtscheidl@univie.ac.at in order to install the website. Information can then be added about geology and mineralogy, about physical and chemical properties of the soil, about flora and fauna as well as soil microbes, and about the history of the mining site as well as about its socio-economic conditions. Articles can be contributed and texts can be commented after registration. Special emphasize is laid on the provenience of the data; they are all linked with the name and affiliation of the contributor.

\section{Conclusion}

BioRem shall document the biodiversity of heavy metal rich sites around the globe, which are the habitats of specialized MTOs. Accordingly, it shall provide a comprehensive inventory of MTOs together with the analysis of environmental conditions, and hence lead to a holistic model of life in heavy metal rich habitats providing observations and research publications. It shall be a source for quotable scientific information of research about adaptation mechanisms of MTOs as well as for applied questions such as gentle remediation by plants and soil microbes. Information will be useful not only for researchers but also for stakeholders and communities, and it will support developing guidelines for either remediation or conservation of habitats.

\section{Acknowledgements}

The authors acknowledge the funding of the work by the EU project Umbrella (EU 226870), by the Austrian Ministery for Science and Research, by the Austrian EAD/ Appear funded project BioRem (Appear 43), and by the OEAD funded project Promote (WTZ-RO 08/2012).

\section{REFERENCES}

[1] D. C. Adriano, "Trace Elements in the Terrestrial Environment,” 2nd Edition, Springer Verlag, Berlin, 2001. http://dx.doi.org/10.1007/978-0-387-21510-5

[2] A. K. Pendias and H. Pendias, "Trace Elements in Soils and Plants,” 3rd Edition, CRC Press, Boca Raton, 2001.

[3] W. H. O. Ernst, "Schwermetallvegetation der Erde,” In: Geobotanica Selecta, Vol. 5, Gustav Fischer Verlag, Stuttgart, 1974.

[4] A. J. M. Baker, "Metal Tolerance,” New Phytologist, Vol. 106, No. S1, 1987, pp. 93-111. http://dx.doi.org/10.1111/j.1469-8137.1987.tb04685.x

[5] A. J. M. Baker and R. R. Brooks, “Terrestrial Plants Which Hyperaccumulate Metallic Elements-A Review of Their Distribution, Ecology and Phytochemistry,” Biorecovery, Vol. 1, 1989, pp. 81-126.

[6] R. R. Brooks, M. F. Chambers, L. J. Nicks and B. H. Robinson, "Phytomining," Trends in Plant Science, Vol. 3, No. 9, 1998, pp. 359-362.

http://dx.doi.org/10.1016/S1360-1385(98)01283-7

[7] S. P. McGrath, "Phytoextraction for Soil Remediation," In: R. R. Brooks, Ed., Plants That Hyperaccumulate Metals, CAB International, Wallingford, 1998, pp. 261-287.

[8] J. Vangronsveld, A. Ruttens, M. Mench, J. Boisson, N. W. Lepp, R. Edwards, C. Penny and D. Van der Lelie, "In Situ Inactivation and Phytoremediation of Metal- and Metalloid-Contaminated Soils: Field Experiments,” In: D. L. Wise and D. J. Trantolo, Eds., Bioremediation of Contaminated Soils, Marcel Dekker, Inc., New York, 2000, pp. 859-885.

[9] A. Van der Ent, "Global Serpentine Ecology Database," 2013. http://www.ultramafic-ecology.org

[10] A. Van der Ent, “Global Metallophyte Database,” 2013. http://www.metallophytes.com

[11] Wikipedia, "List of Hyperaccumulators,” 2013. http://en.wikipedia.org/wiki/List_of_hyperaccumulators 